\title{
SPESIES CAPUNG (ORDO ODONATA) PADA PERTANAMAN PADI DI BEBERAPA SAWAH SEKITAR DENPASAR, BALI
}

\section{SPECIES OF DRAGONFLIES (ODONATA ORDER) FOR RICE PLANTATIONS IN SOME RICE FIELD AROUND DENPASAR, BALI}

\author{
Ni Made Suartini ${ }^{1}$, Ni Wayan Sudatri ${ }^{2}$ \\ ${ }^{1}$ Laboratorium Taksonomi Hewan Jurusan Biologi Fakultas MIPA Universitas Udayana \\ ${ }^{2}$ Laboratorium Fisiologi Hewan Jurusan Biologi Fakultas MIPA Universitas Udayana \\ email: made_suartini@unud.ac.id
}

\begin{abstract}
ABSTRAK
Capung merupakan salah satu serangga (Insekta) yang termasuk ordo Odonata. dan terdiri atas subordo Anisoptera (capung) serta subordo Zygoptera (capung jarum). Habitatnya sangat luas termasuk juga pada habitat sawah. Capung dan capung jarum merupakan serangga predator, baik dalam bentuk nimfa maupun dewasa sehingga sangat penting perannya dalam menjaga keseimbangan ekosistem. Penelitian ini dilakukan bertujuan untuk mengetahui spesies-spesies capung yang terdapat pada pertanaman padi di sawah sekitar wilayah Denpasar. Pengambilan sampel dilakukan dengan penangkapan menggunakan jaring serangga (insect nets) pada pertanaman padi yaitu saat pagi hari mulai pukul 08.00 sampai 11.00 WITA, dan sore hari mulai pukul 15.00 sampai 17.00 WITA. Sampel capung yang diperoleh kemudian diawetkan untuk diidentifikasi dengan mengamati karakter morfologinya berdasarkan acuan Hanum et al. (2013) dan Sigit et al. (2013). Spesies capung yang ditemukan pada area pertanaman padi di beberapa sawah sekitar Denpasar adalah sebanyak 8 spesies yang termasuk kedalam 2 yaitu subordo Anisoptera (5 spesies) dan subordo Zygoptera (3 spesies), Spesies dari subordo Anisoptera ( Potamarcha congener) hanya ditemukan pada pertanaman padi di Denpasar timur.
\end{abstract}

Kata kunci: serangga, habitat capung, identifikasi, karakter morfologi

\section{ABSTRACT}

Dragonfly is an insect which belongs to the Odonata order and consists of the Anisoptera suborder (dragonflies) and Zygoptera suborder (damselflies). Its habitat is very wide including in the rice field. Dragonflies and Damselflies are predatory insects, both in the form of nymphs and adults, so their role is very important in maintaining the balance of the ecosystem. The research was conducted to finding out the dragonfly species found in rice plantations in rice fields around the Denpasar area. Sampling was done by catching using insect nets on rice plantations, in the morning from 08.00 to 11.00 WITA, and in the afternoon from 15.00 to 17.00 WITA. Dragonfly samples obtained were then preserved to be identified by observing the morphological characters based on Hanum et al. (2013), and Sigit et al. (2013). Dragonfly species found in rice plantations areas in several rice fields around Denpasar are as many as 8 species which are included in 2 suborder, namely Anisoptera suborder (5 species) and Zygoptera suborder (3 species), Species of Anisoptera suborder (Potamarcha congener) only found in rice plantations in East Denpasar.

Keywords: insects, dragonfly habitat, identification, morphological characters

\section{PENDAHULUAN}

Habitat capung ada dua yaitu akuatik dan non akuatik serta habitatnya sangat luas termasuk juga pada habitat sawah (Orr, 2005). Capung mempunyai peranan penting pada ekosistem persawahan karena merupakan serangga predator, baik dalam bentuk nimfa maupun dewasa, dan memangsa berbagai spesies serangga serta organisme lain termasuk serangga hama tanaman padi. Dalia dan Leksono (2014) menyebutkan bahwa capung berperan sebagai predator berbagai Arthropoda di pertanian, terutama bagi ordo Lepidoptera, Hymenoptera, Hemiptera, Orthoptera, dan Diptera. Capung juga menjadi mangsa bagi Arthropoda, misalnya Araneida, dan vertebrata. Menurut Subramanian (2009), imago capung adalah predator aerial yang memburu mangsanya dengan terbang berulang-ulang. Capung jarum juga berperan sebagai musuh alami yang dapat mengurangi populasi hama tanaman pangan

Sekitar 5000 spesies capung tersebar di seluruh dunia dan sekitar 700 spesies terdapat di Indonesia (Sigit et al., 2013). Penelitian tentang capung di Bali yang dilakukan oleh Wijayanto dkk. (2016), di resort Taman Nasional Bali Barat (TNBB) menemukan capung sebanyak 26 spesies yang termasuk ke dalam 5 famili, yaitu Aeshnidae (1 spesies), Libellulidae (18 spesies), Chlorochyphidae (1 spesies), Coenagrionidae (5 spesies), dan Protoneuridae (1 spesies). Habitat tempat penelitian yaitu rawa hutan musim, rawa mangrove, savana, dan hutan musim.

Terdapat beberapa faktor yang mempengaruhi keberadaan capung dan penyebaran spesies-spesies capung. Menurut McPeek (2008) beberapa faktor yang membatasi keberadaan serta penyebaran capung dalam suatu habitat adalah tipe habitat, ketersediaan pakan, serta interaksi yang berkaitan dengan siklus hidup capung. Semua faktor tersebut saling berhubungan dan mempengaruhi satu sama lainnya.

Suhu, kelembaban, intensitas cahaya dan kecepatan angin juga berpengaruh terhadap keberadaan capung. Faktor-faktor tersebut akan menjadi pembatas penyebaran beberapa spesies capung, terutama spesies capung endemik yang memiliki faktor fisik yang spesifik. Kondisi fisik habitat yang optimal akan mempengaruhi keberadaan spesies capung (Crumrine et al., 2008).

Sawah merupakan ekosistem lahan basah buatan dan salah satu ekosistem perairan tergenang (Puspita dkk, 2005). Di Provinsi Bali sampai saat ini tercatat $81.908 \mathrm{Ha}$ $(14,4 \%)$ lahan persawahan yang dominan ditanami padi (Mulyadi, 2011). Sawah merupakan salah satu habitat dari capung. Keberadaan sawah saat ini sudah semakin berkurang karena terjadinya alih fungsi lahan persawahan. Himpunan Kerukunan Tani Indonesia (HKTI) mencatat sedikitnya 800 hektar sawah per tahun beralih fungsi. Lebih lanjut disebutkan bahwa alih fungsi lahan 
persawahan ini sangat memungkinkan menjadi ancaman bagi kelestarian alam Bali (Balipost, 2011).

Pupuk dan pestisida kimia juga menjadi hal yang tidak dapat dipisahkan dengan lingkungan sawah sebagai salah satu habitat capung sehingga akan bepengaruh juga terhadap spesies capung yang ada di habitat tersebut. Selain itu data mengenai spesies capung yang ada di Bali terutama di pertanaman padi belum banyak diungkap. Dengan demikian perlu dilakukan penelitian terkait keberadaan capung di pertanaman padi sawah terutama di sektar wilayah Denpasar sehingga diperoleh data tentang spesies-spesies capung yang terdapat di lokasi tersebut dan juga menambah data keberadaan spesies-spesies capung yang ada di Bali.

\section{MATERI DAN METODE}

\section{Pengambilan Sampel}

Pengambilan sampel capung dilakukan pada pertanaman padi di beberapa sawah sekitar Denpasar dan sampel pada setiap lokasi diambil sebanyak tiga kali. Metode penelitian yang digunakan adalah metode deskriptif dengan cara koleksi langsung menggunakan jala serangga (insect net) yaitu pagi hari pukul 08.00 sampai 11.00 WIB, dan sore hari mulai pukul 15.00 sampai 17.00 WIB. Sampel yang diperoleh dimasukkan dalam stoples pembius yaitu stoples yang telah diberi kapas dan kloroform. Setelah di bius, sampel capung dipindahkan ke dalam kertas papilot berukuran 30 × $20 \mathrm{~cm}$ dengan posisi sayap terlipat di atas tubuh, pada setiap amplop disimpan satu individu capung. Setelah itu, sampel yang didapat dibawa ke laboratorium untuk identifikasi.
Pada saat pengambilan sampel juga dilakukan pengukuran koordinat tiap lokasi, serta faktor lingkungan lainnya yaitu suhu udara, kelembaban udara, kandungan oksigen air (DO), pH air dan suhu air.

\section{Identifikasi Sampel}

Sampel capung yang diperoleh dibawa ke Laboratorium Taksonomi Hewan Jurusan Biologi Fakultas MIPA Universitas Udayana, kemudian dilakukan pengamatan morfologi secara langsung dan dengan "dissecting mocroscop' untuk melihat dan mencatat semua karakter yang diperlukan untuk keperluan identifikasi. Setiap spesies yang teridentifikasi dibuat dokumentasinya menggunakan kamera digital dan juga kamera mikroskup merk OptiLab yang langsung terhubung dengan laptop.

\section{Analisis Data}

Data kualitatif berupa semua karakter morfologi yang tercatat kemudian diidentifikasi berdasarkan acuan Hanum et al. (2013), Ansori (2009) dan Sigit et al. (2013), selanjutnya dianalisis secara deskriftif. Data faktor lingkungan ditampilkan dalam bentuk tabel serta dideskripsikan

HASIL

Spesies capung yang ditemukan pada area pertanaman padi di beberapa sawah sekitar Denpasar adalah sebanyak 8 spesies yang termasuk kedalam 2 subordo. Subordo Anisoptera ditemukan sebanyak 5 spesies dimana spesies Potamarcha congener hanya ditemukan pada pertanaman padi di Denpasar timur. Semua spesies yang ditemukan disajikan pada Tabel 1 dan Tabel 2

Tabel 1. Spesies capung yang ditemukan di pertanaman padi di wilayah Denpasar

\begin{tabular}{|c|c|c|c|c|c|c|c|}
\hline \multirow[b]{2}{*}{$\underline{\text { Subordo }}$} & \multirow[b]{2}{*}{$\underline{\text { Famili }}$} & \multirow[b]{2}{*}{$\underline{\text { Spesies }}$} & \multirow{2}{*}{$\underline{\text { Nama }}$} & \multicolumn{4}{|c|}{ Lokasi ditemukan } \\
\hline & & & & I & $\underline{\mathrm{II}}$ & $\underline{\text { III }}$ & IV \\
\hline \multirow[t]{5}{*}{ Anisoptera } & $\underline{\text { Libellulidae }}$ & Pantala flavescens & Capung kembara & $\underline{\sqrt{ }}$ & $\underline{\bar{V}}$ & $\underline{\underline{V}}$ & $\underline{V}$ \\
\hline & & Potamarcha congener & $\begin{array}{c}\text { Capung sambar } \\
\text { perut pipih }\end{array}$ & $\underline{\bar{V}}$ & $\bar{z}$ & $\bar{z}$ & $\bar{z}$ \\
\hline & & Crocothemis servilia & $\begin{array}{l}\text { Capung sambar } \\
\text { garis hitam }\end{array}$ & $\sqrt{ }$ & $\sqrt{ }$ & $\sqrt{ }$ & $\sqrt{ }$ \\
\hline & & Brachithemis contaminata & $\begin{array}{l}\text { Capung sayap } \\
\text { oranye }\end{array}$ & $\sqrt{ }$ & $\sqrt{ }$ & $\sqrt{ }$ & $\sqrt{ }$ \\
\hline & & Orthetrum sabina & $\begin{array}{c}\text { Capung sambar } \\
\text { hijau }\end{array}$ & $\sqrt{ }$ & $\sqrt{ }$ & $\sqrt{ }$ & $\sqrt{ }$ \\
\hline \multirow[t]{3}{*}{ Zygoptera } & Coenagrionidae & Ischnura senegalensis & $\begin{array}{l}\text { Capung jarum } \\
\text { sawah }\end{array}$ & $\sqrt{ }$ & $\sqrt{ }$ & $\sqrt{ }$ & $\sqrt{ }$ \\
\hline & & Agriocnemis femina & $\begin{array}{l}\text { Capung jarum } \\
\text { centil }\end{array}$ & $\sqrt{ }$ & $\sqrt{ }$ & $\sqrt{ }$ & $\sqrt{ }$ \\
\hline & & Agriocnemis pygmaea & $\begin{array}{l}\text { Capung jarum } \\
\text { kecil }\end{array}$ & $\sqrt{ }$ & $\sqrt{ }$ & $\sqrt{ }$ & $\sqrt{ }$ \\
\hline
\end{tabular}

Keterangan: II Denpasar timur, II= Denpasar utara, III= Denpasar selatan, IV= Denpasar bara

Tabel 2. Spesies capung yang ditemukan berdasarkan waktu pengambilan sampel

\begin{tabular}{|c|c|c|c|c|c|c|c|c|}
\hline \multirow{3}{*}{ Spesies } & \multicolumn{8}{|c|}{ Lokasi ditemukan } \\
\hline & \multicolumn{2}{|c|}{$\mathrm{I}$} & \multicolumn{2}{|c|}{ II } & \multicolumn{2}{|c|}{ III } & \multicolumn{2}{|c|}{ IV } \\
\hline & $\mathrm{P}$ & $\mathrm{S}$ & $\mathrm{P}$ & $\mathrm{S}$ & $\mathrm{P}$ & $\mathrm{S}$ & $\mathrm{P}$ & $\mathrm{S}$ \\
\hline Pantala flavescens & $\sqrt{ }$ & $\sqrt{ }$ & $\sqrt{ }$ & $\sqrt{ }$ & $\sqrt{ }$ & $\sqrt{ }$ & $\sqrt{ }$ & $\sqrt{ }$ \\
\hline Potamarcha congener & $\sqrt{ }$ & $\sqrt{ }$ & - & - & - & - & - & - \\
\hline Crocothemis servilia & $\sqrt{ }$ & $\sqrt{ }$ & $\sqrt{ }$ & $\sqrt{ }$ & $\sqrt{ }$ & $\sqrt{ }$ & $\sqrt{ }$ & $\sqrt{ }$ \\
\hline Brachithemis contaminata & $\sqrt{ }$ & $\sqrt{ }$ & $\sqrt{ }$ & $\sqrt{ }$ & $\sqrt{ }$ & $\sqrt{ }$ & $\sqrt{ }$ & $\sqrt{ }$ \\
\hline Orthetrum sabina & $\sqrt{ }$ & $\sqrt{ }$ & $\sqrt{ }$ & $\sqrt{ }$ & $\sqrt{ }$ & $\sqrt{ }$ & $\sqrt{ }$ & $\sqrt{ }$ \\
\hline Ischnura senegalensis & $\sqrt{ }$ & $\sqrt{ }$ & $\sqrt{ }$ & $\sqrt{ }$ & $\sqrt{ }$ & $\sqrt{ }$ & $\sqrt{ }$ & $\sqrt{ }$ \\
\hline Agriocnemis femina & $\sqrt{ }$ & $\sqrt{ }$ & $\sqrt{ }$ & $\sqrt{ }$ & $\sqrt{ }$ & $\sqrt{ }$ & $\sqrt{ }$ & $\sqrt{ }$ \\
\hline Agriocnemis pygmaea & $\sqrt{ }$ & $\sqrt{ }$ & $\sqrt{ }$ & $\sqrt{ }$ & $\sqrt{ }$ & $\sqrt{ }$ & $\sqrt{ }$ & $\sqrt{ }$ \\
\hline
\end{tabular}




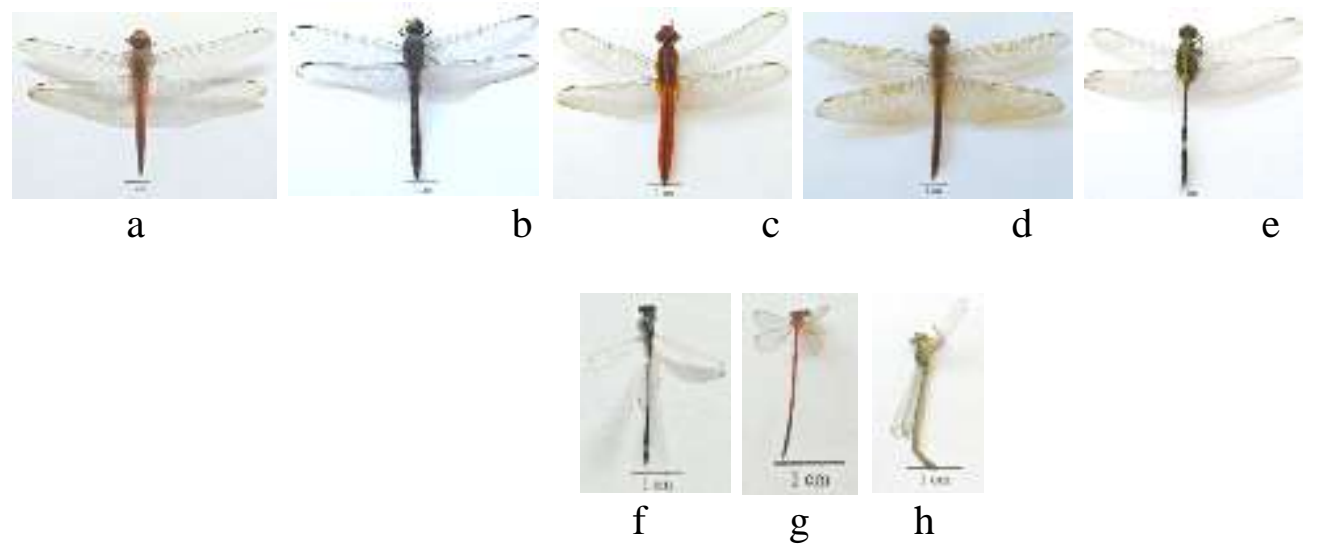

Gambar 1. Spesies capung yang ditemukan

$\mathrm{a}=P$. flavescens, $\mathrm{b}=P$. congener, $\mathrm{c}=C$. servilia, $\mathrm{d}=B$. contaminata, $\mathrm{e}=O$. sabina $\mathrm{f}=I$. senegalensis, $\mathrm{g}=$ A. femina, $\mathrm{h}=$ A. pygmaea

Kondisi lingkungan di sekitar pertanaman padi tempat pengambilan sampel berbeda-beda. Di Denpasar timur dengan koordinat S 3'38'36', E 115'15'30', terdapat beberapa pohon, diantaranya pohon kayu santan, bambu, semak-semak, dan juga tanaman kangkung. Di Denpasar utara dengan koordinat S 8'36'19', E 115'13'31', terdapat pohon kelapa, semak-semak, rumput gajah dan juga tanaman kangkung. Di Denpasar selatan dengan koordinat S 8'41'35', E 115'14'32', terdapat pohon pisang dan semak-semak sedangkan di Denpasar barat dengan koordinat S 8'39'42', E 115'10'32'’terdapat pohon pisang, semak-semak dan tanaman kangkung. Hasil pengukuran beberapa faktor lingkungan lainnya pada lokasi pengambilan sampel tercantum pada Tabel 3.

Tabel 3. Rata-rata Fakor lingkungan yang terukur di semua lokasi

\begin{tabular}{lcccccccc}
\hline \multirow{2}{*}{ Spesies } & \multicolumn{8}{c}{ Lokasi } \\
\cline { 2 - 10 } & \multicolumn{2}{c}{ I } & \multicolumn{1}{c}{ II } & \multicolumn{3}{c}{ III } & \multicolumn{3}{c}{ IV } \\
\cline { 2 - 10 } & P & S & P & S & P & S & P & S \\
\hline Suhu udara $\left({ }^{0} \mathrm{C}\right)$ & 25 & 29 & 29 & 33 & 28 & 31 & 27,5 & 30 \\
Kelembaban udara (\%) & 82 & 70 & 69 & 55 & 79 & 62 & 78 & 70 \\
Suhu air $\left({ }^{0} \mathrm{C}\right)$ & 24 & 26 & 25 & 29 & 24 & 27 & 25 & 29 \\
pH & 7.5 & 7 & 7 & 7,5 & 7,5 & 7,5 & 7 & 7 \\
DO & 5,2 & 5,5 & 7 & 8,5 & 6 & 6.5 & 5,3 & 6,5 \\
\hline
\end{tabular}

\section{PEMBAHASAN}

Hasil pengamatan terhadap ke delapan spesies capung yang ditemukan pada semua lokasi, Orthetrum sabina (Subordo Anisoptera) adalah salah satu spesies yang terdapat di semua lokasi dan teramati dengan jumlah individu terbanyak serta ditemukan baik pada pagi maupun sore hari. Beberapa hasil penelitian lainnya juga menyebutkan spesies tersebut hampir selalu dijumpai. Penelitian Ansori (2009) mendapatkan O. sabina adalah spesies yang dominan ditemukan dan Rachman (2016) mendapatkan bahwa $O$. sabina mempunyai indeks diversitas tertinggi. Menurut Susanti (1998), O. sabina hidup soliter dengan persebaran yang luas dan mempunyai toleransi yang tinggi terhadap perubahan kondisi lingkungan. Sigit et al. (2013) juga menyatakan bahwa spesies tersebut juga dapat hidup pada kondisi perairan yang tercemar dan Wijayanto dkk. (2016), menyebutkan bahwa banyaknya serangga-serangga kecil sebagai faktor yang tidak kalah penting mempengaruhi kehidupan capung karena memungkinkan tersedianya kebutuhan makanan bagi capung.

O. sabina cenderung dijumpai pada daerah yang terpapar sinar matahari langsung. Spesies tersebut diketahui mampu hidup hampir di semua habitat berair sampai ketinggian $2300 \mathrm{~m}$ dpl misalnya kolam, rawa, danau, irigasi dan habitat berair lainnya serta toleran terhadap salinitas tinggi dan habitat yang terganggu (Mitra, 2013). O. sabina merupakan capung predator yang cukup ganas. Capung tersebut sering memangsa serangga lain, spesies capung lainnya atau spesies yang sama (Rahadi $e t$ $a l, 2013)$. Pada saat penelitian, teramati spesies tersebut sedang memangsa capung dari spesies yang sama $(O$. sabina) dan juga spesies lain yaitu Pantala flavescens.

Capung (subordo Anisoptera) teramati terbang pada permukaan air atau hinggap pada tanaman padi dan juga pada semak serta tanaman lain yang ada di dekat pertanaman padi. Capung subordo Zygoptera juga teramati hinggap pada tanaman padi tetapi lebih banyak ditemukan pada tumbuhan yang terdapat di sekitar pertanaman padi diantaranya pada tanaman rumput-rumputan (Poaceae) dan tanaman kangkung (Ipomoea aquatica) serta cendrung lebih pasif dibandingkan dengan subordo Anisoptera.

Capung jarum (subordo Zygoptera) yang ditemukan pada penelitian teramati jumlah individunya tidak sebanyak capung (subordo Anisoptera). Capung jarum juga merupakan predator pada pertanaman padi dan dianggap berperan penting dalam mengendalikan hama pada pertanaman padi secara alami, karena selain spesiesnya sangat beragam, jumlahnyapun dapat melimpah di alam. Nimfa capung jarum hidup di air dan dapat naik ke batang padi untuk mencari nimfa wereng dan pada stadia dewasa umumnya terbang di bawah daun padi untuk mencari serangga yang sedang terbang (Subaidi et al, 2012). Capung jarum yang ditemukan semuanya termasuk famili Coenagrionidae dimana menurut Orr 
(2003), famili tersebut merupakan famili terbesar jumlahnya dan penyebarannya merata di seluruh dunia sehingga mendukung ditemukannya anggota dari famili tersebut pada penelitian ini.

Famili Coenagrionidae merupakan salah satu famili capung dimana sebagian besar spesiesnya ditemukan di habitat air yang tidak mengalir (Kalkman dan Orr 2013), sehingga famili Coenagrionidae dapat hidup di berbagai tipe habitat baik pada habitat perairan mengalir maupun perairan tidak mengalir. Kemampuan adaptasi yang tinggi dari famili tersebut menyebabkan tingginya jumlah spesies yang ditemukan di berbagai habitat.

Faktor yang mempengaruhi keberadaan capung dan persebarannya adalah sumber makanan dan kondisi habitat. Menurut McPeek (2008) beberapa faktor yang membatasi keberadaan serta penyebaran capung dalam suatu habitat adalah tipe habitat, ketersediaan pakan, serta interaksi yang berkaitan dengan siklus hidup capung. Semua faktor tersebut saling berhubungan dan mempengaruhi satu sama lainnya. Capung merupakan serangga yang termasuk dalam golongan hewan yang memperoleh panas dari lingkungan untuk menaikkan suhu tubuhnya (Dharmawan, 2005), sehingga suhu lingkungan menentukan suhu tubuh bagi capung. Capung sendiri memiliki kemampuan untuk mengatur suhu tubuhnya dimana jika suhu lingkungan rendah di bawah ambang toleransi, capung akan mati karena metabolisme tubuh terhambat. Jika suhu lingkungan rendah namun masih dapat ditoleransi oleh capung metabolisme tubuh akan terbatas, sehingga aktivitas capung menjadi berkurang. Pada saat penelitian teramati jika suhu udara terlalu panas, capung jarang teramati beterbangan. Tetapi suhu lingkungan terukur adalah berkisar antara $25^{\circ} \mathrm{C}$ sampai $31^{\circ} \mathrm{C}$, yang mana masih berada pada ambang batas suhu yang diperlukan untuk kehidupan capung.

Kandungan oksigen terlarut juga berpengaruh terhadap kehidupan capung terutama pada fase telur sampai nimfa karena pada fase tersebut berada di perairan. Stadium pradewasa capung membutuhkan air sebagai media hidupnya (Orr, 2005). Nilai kandungan oksigen terlarut di semua lokasi pengambilan sampel berkisar antara 5,3-8,5 dimana berada di atas batas terendah kadar DO bagi organism. Menurut Suwondo et al., (2005), batas terendah kadar oksigen terlarut bagi organisme ialah 4 ppm. Sedangkan kisaran $\mathrm{pH}$ terukur adalah 7-7,5 dimana dapat dikatakan masih mendukung untuk kehidupan nympha capung karena menurut Effendi (2003), pH yang disukai oleh hewan perairan yaitu 7-8,5.

\section{SIMPULAN}

Spesies capung yang ditemukan pada area pertanaman padi di beberapa sawah sekitar Denpasar adalah sebanyak 8 spesies yang termasuk kedalam 2 subordo. Subordo Anisoptera ditemukan sebanyak 5 spesies dimana spesies Potamarcha congener hanya ditemukan pada pertanaman padi di Denpasar timur

\section{UCAPAN TERIMAKASIH}

Terimakasih disampaikan pada Universitas udayana melalui Fakultas MIPA dengan dana DIPA BLU Universitas Udayana dengan Surat Perjanjian Penugasan Pelaksanaan Kegiatan Penelitian Hibah Unggulan Program Studi Nomor: 2021/UN14.2.8.II/LT/2018, tanggal 26 Maret 2018 yang telah mendanai penelitian ini.

\section{DAFTAR PUSTAKA}

Ansori, I. 2009. Kelimpahan dan Dinamika Populasi Odonata Berdasarkan Hubungannya dengan Fenologi Padi di Beberapa Persawahan Sekitar Bandung Jawa Barat. Jurnal Exacta. Vol 2 (2): 69.

Balipost. 2011. Ketahanan Pangan Terancam. Alih Fungsi Sawah tak Terkendali. http://www.balipost.co.id/mediadetail.php?module $=$ detailberita\&kid $=10 \& \mathrm{id}=59551$

Crumrine, P. W., Switzer, P. V., and Crowley, P. H. 2008. Structure and Dynamics of Odonate Communities. Accesing Habitat, Responding to Risk, and Enabling Reproduction. Aguilar, A.C. (eds). Dragonflies and Damselflies: Model Organisms for Ecological and Evolutionary Research. Oxford University Press Inc. New York.

Dalia, B. P. I. dan A. S. Leksono. 2014. Interaksi Antara Capung dengan Arthropoda dan Vertebrata Predator di Kepanjen, Kabupaten Malang. Jurnal Biotropika. Vol. 2 (1): 26-30.

Dharmawan, A., Ibrohim, H. Tuarita, H. Suwono dan P. Susanto. 2005. Ekologi Hewan. Malang: Universitas Negeri Malang.

Effendi, H. 2003. Telaah Kualitas Air. Bagi Pengelolaan Sumber Daya Alam dan Lingkungan Perairan. Kanisius. Yogyakarta.

Hanum, S. O., S. Salamah Dan Dahelimi. 2013. JenisJenis Capung (Odonata) Di Kawasan Taman Satwa Kandi Kota Sawahlunto, Sumatera Barat. Jurnal Biologi Universitas Andalas (J. Bio. UA.). 2(1) : 71-76.

Kalkman, V and Orr, A. G. 2013. Field guide to the damselflies of New Guinea. Scholma Druk BV Bedum

McPeek, M. A. 2008. Ecological Factors Limiting The Distributions and Abundances of Odonata. Aguilar, A.C. (eds). Dragonflies and Damselflies: Model Organisms for Ecological and Evolutionary Research. Oxford University Press Inc. New York.

Mitra, A. 2013. Orthetrum sabina. The IUCN Red List of

Threatened Species 2013: e.T165470A17533255. http://dx.doi.org/10.2305/IUCN.UK.20131.RLTS. T165470A17 533255.en. Diakses pada 09 Desember 2016

Mulyadi. 2011. Upaya Bali Mengendalikan Alih Fungsi Lahan

Pertanian. http://www.tataruangindonesia.com/fullpost/pertan ian/1324987677/upaya-bali-mengendalikan-alihfungsi-lahan-pertanian.html

Orr, A. G. 2003. A guide to the dragonflies of Borneo their identification and biology. Natural History Publications (Borneo). Kinabalu

Orr, A. G. 2005. Dragonfies of Paninsular Malaysian and Singapore. Natural History Publication (Borneo). Kota Kinabalu.

Puspita L, E. Rahmawati, I. N. N. Suryadiputra dan A. A. Meutia. 2005. Lahan Basah Buatan Di Indonesia. Wetlands International Indonesia Programmed an Ditjen PHKA.

Rachman, H.T., and A.Rohman. 2016. Dragonflies Diversity (Odonata) in Menoreh Karst Central Java - Yogyakarta. Int'l Journal of Advances in Agricultural \& Environmental Engg. (IJAAEE) Vol. 3 (2):255-258

Sigit, W., B. Feriwibisono, M. P. Nugrahani, B. Putri dan T, Makitan. 2013. Naga Terbang Wendit. Indonesia Dragon Society. 
Subramanian, K.A. 2009. Dragonflies of India-a Field Guide. India Offset Press. New Delhi.

Subaidi, A., S. Hartati dan U. Humaedah. 2012. Mengenal Predator Utama Pada Pertanaman Padi Balai Besar Pengkajian Dan Pengembangan Teknologi Pertanian Badan Penelitian Dan Pengembangan Pertanian Kementerian Pertanian.

Susanti, S. 1998. Seri Panduan Lapangan: Mengenal Capung. Bogor:Puslitbang Biologi-LIPI.

Suwondo, E, Febrita, dan F, Sumanti. 2005. .Struktur Komunitas Gastropoda Pada Hutan Mangrove di Pulau Sipora Kabupaten Kepulauan Mentawai Sumatera Barat, Jurnal Biogenesis, Vol. 2 (1): 2529.

Wijayanto, A.G., N.A. Nafisah, Z. Laily dan M.N. Zaman. 2016. Inventarisasi Capung (Insecta: Odonata) dan Variasi Habitatnya di Resort Tegal Bunder dan Teluk Terima Taman Nasional Bali Barat (TNBB). Prosiding. Seminar Nasional Pendidikan dan Saintek. 427-434. 